\title{
A 3D illustrative of scanning electron microscopy on dried duku microstructural evaluation
}

\author{
Laila Rahmawati $^{1 *}$, Daniel Saputra ${ }^{2}$,Kaprawi Sahim ${ }^{3}$, and Gatot Priyanto ${ }^{2}$ \\ ${ }^{1}$ Research Center of Appropriate Technology, Indonesian Institute of Sciences, Subang, West Java, \\ 41243, Indonesia \\ ${ }^{2}$ Collage of Agriculture, Universitas Sriwijaya, Indralaya, Palembang, 30862, Indonesia \\ ${ }^{3}$ Collage of Engineering, Universitas Sriwijaya, Indralaya, Palembang, 30862, Indonesia
}

\begin{abstract}
The previous research showed that the duku's peel which dried using infrared radiation could extend the shelf life up to 25 days. The aims of this study to illustrate using 3D visual analysis on microstructural of dried duku's peel that had dried using infrared radiation. Scanning Electron Microscopy (SEM) technique with magnifications of $\mathrm{x} 100$, x500, and $\mathrm{x} 2500$, resolution of $10 \mu \mathrm{m}, 50 \mu \mathrm{m}$, and $100 \mu \mathrm{m}$ in dried duku's peel using infrared radiation at a distance of infrared emitter (IRE) $6 \mathrm{~cm}$ and $10 \mathrm{~cm}$ with an exposure temperature of $300^{\circ} \mathrm{C}$ for $60 \mathrm{~s}$. The $3 \mathrm{D}$ visual illustration using Mountain Maps Program shows the porosity value on $6 \mathrm{~cm}$ distance of IRE, with $300^{\circ} \mathrm{C}$ of IRE temperature and $60 \mathrm{~s}$ of exposure time has $90,91 \%$, while the $10 \mathrm{~cm}$ distances of IRE, $300^{\circ} \mathrm{C}$ of IRE temperature and $60 \mathrm{~s}$ of exposure time has $146,95 \%$. It could conclude that from 3D illustrative of SEM by reconstructing a single image into pseudo-color view and a profile curve produced at drying distance of $6 \mathrm{~cm}, 300^{\circ} \mathrm{C}$, and $60 \mathrm{~s}$ has lower porosity value, and more stable contour when compared to drying with a distance of $10 \mathrm{~cm}, 300^{\circ} \mathrm{C}, 6 \mathrm{~s}$, and control treatment. This condition could confirm the previous research. The duku's peel microtexture condition which was exposed by IRE could create a dry condition as shell-likeness that could maintain the fruit quality and prolong the shelf life.
\end{abstract}

\section{Introduction}

Duku (Lansium domesticum corr) is an exotic tropical fruit that could be found in South Sumatera. Duku has a special characteristic which has unique taste. Duku has a short shelf life when stored in room temperature, it's around 3-7 days. Duku is also easy to attack by microbes. Nowadays, there were several methods to prolong the shelf life of duku. The method that had been reported was drying process. The drying process is categorized by food thermal processing. In recent years, Infrared radiation in one of food thermal process which has a good potential for food. Infrared radiation had been implemented to reduce the water content, securing and ensuring the food quality with low energy consumption and short-time processing [1]. Infrared radiation has a unique characteristic which could create

* Corresponding author: laila.rahmawati53@gmail.com 
a dry skin with hit the skin only without raising the flesh temperature in a short time [2]. In previous research, infrared radiation could create a "shell likeness" on Duku's peel and prolong the shelf life up to 25 days [3]. During forming "shell likeness" on duku's peel, there were microstructural and texture changes.

The study of the microstructure has already taken in recent years. The microstructure could profound the chemical content and physical properties changes either by due to the moisture loss, thermo-physical and thermo-chemical heat mass transfer. The changes of structural and microstructural of duku's peel could impact the changes of porosity. In the previous research, the mechanical properties and textural of food correlated the porosity. Huang and Clayton [4], reported that the size pore, pore size distribution, and porosity variation have a textural characteristic significant effect of dried food.

In this research, the influence of processing conditions on duku would be recognized by microscopy technique. In the last decades, the microscopy technique could investigate not only food structure but also the types of information that could glean regarding the structure. Microscopic images are becoming common because of the power of threedimensional imaging, greater image analysis to derive the quantitative of microstructural information, and dynamic studies of in situ microscopy [5]. One tool which has been widely employed for food and biological microstructure is electron microscopy. Scanning electron microscopy (SEM) is a useful tool which could visualize food texture and structure because it has a combination within the light microscopy (LM) and transmission electron microscopy (TEM) [6,7]. The scanning electron microscopy technique was picked in this research because it could be used to analyze the microstructure changes during infrared radiation heating on duku's peel.

This research aimed to evaluate the microstructure of dried duku's peel with 3D illustration of scanning electron microscopy and to confirm the results of the chemical, physical and microstructural that had previously performed in the drying of duku's peel using infrared radiation.

\section{Materials and methods}

\subsection{Samples preparation}

Selected Duku fruit used in this research from Komering Regency, South Sumatera Province, Indonesia. Duku was selected from physical appearance which has yellowish colour peel without any blemish and microorganism contamination. The diameter of duku were ranged from 2,5 to $3,5 \mathrm{~cm}$. The samples were uniformed at 2 days after harvest before being processed using infrared.

\subsection{Infrared radiation system}

The infrared radiation system in detail has been explained in previous research [6/3]. Three duku were exposed in a pair infrared emitter (IRE) with the distance $6 \mathrm{~cm}$ and $10 \mathrm{~cm}$. The IRE was placed at the top and bottom between basket fruit. The fruits were exposed IRE for $300^{\circ} \mathrm{C}$ for $60 \mathrm{~s}$. After exposing with IRE, dukus were stored in a controlled showcase (range $11-15^{\circ} \mathrm{C}$ ) for 25 days then the chemical characteristic and physical properties were measured in two days ranged. The measure of chemical characteristics and physical properties also already mentioned in Rahmawati et al. [8]. 


\subsection{Scanning Electron Microscopy (SEM) analysis}

Before SEM analysis, the duku's peel was dried with freeze dryer method and then was cut longitudinally then observed using Scanning Electron Microscope (SEM, JEOL ${ }^{\circledR}$ serial number 6510 LA) with magnifications of $\times 100, x 500$, and $x 2500$ and resolution of $10 \mu \mathrm{m}$, $50 \mu \mathrm{m}$, and $100 \mu \mathrm{m}$.

The result from SEM was analyzed using the Mountain Map Program ${ }^{\circledR}$ version 7 to illustrate the $3 \mathrm{D}$ visual. The $3 \mathrm{D}$ visual illustrative was used to measure the number of particles, density, projected area (void), the volume of void, the volume of materials, and porosity. The $3 \mathrm{D}$ visual stages with the Mountain Map Program were carried out by measuring manual measurement and analyzing the particle with reconstructed from a single image. The reconstructed from a single image then analyze into a pseudo-color view of the surface to measure the deepest void in duku's microstructure, then illustrate into 3D visual. The pseudo-color reconstructed then extracted to measure the profile curve.

\section{Result and discussion}

Drying using infrared radiation has been reported $[1,2,9,10]$ especially on duku fruit for prolonging the shelf life [8] and the effect on chemical and physical properties on duku fruit [3]. The effect of infrared drying on the microstructural and texture by means of SEM analysis has been published [11].
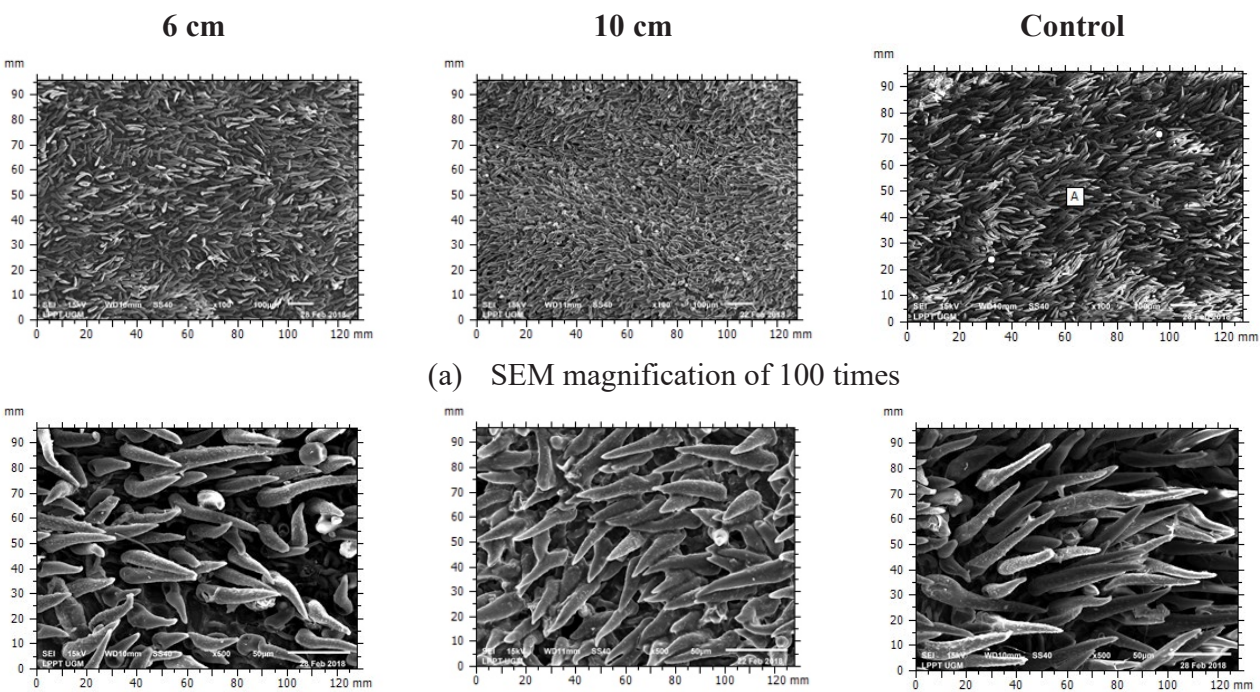

(a) SEM magnification of 100 times
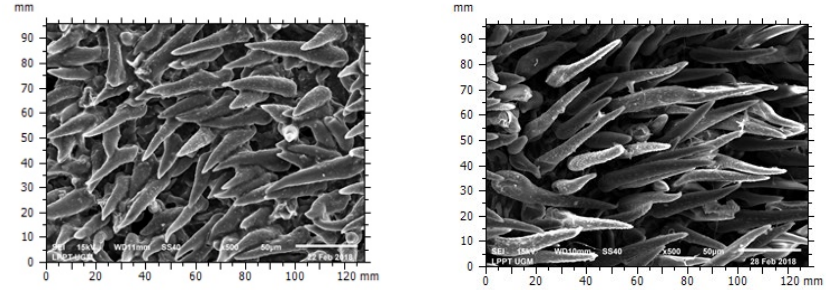

(b) SEM magnification of 500 times
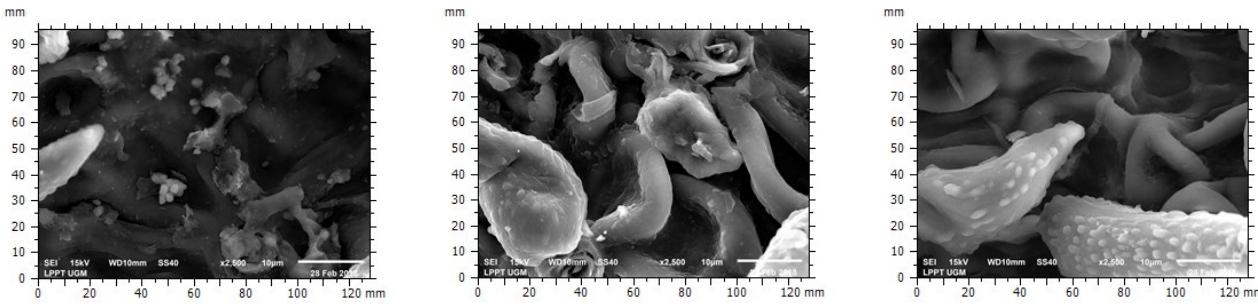

(c)SEM magnification of 2500 times

Fig. 1. Scanning Electron Microscopy manual measurement of duku's peel 
The microstructural evaluation of duku's texture using SEM analysis with the magnification 100 times, 500 times, and 2500 times and resolution of $10 \mu \mathrm{m}, 50 \mu \mathrm{m}$, and $100 \mu \mathrm{m}$. The SEM results were shown in Fig. 1. Visually, the result could be seen that infrared radiation changes the microstructure of duku's peel. The magnification of 500 times could be identified that the cell structure of duku's peel changes to the texture microstructure.

Visually, there was an exfoliation on epidermal cells on duku's peel. The exfoliation on the cuticle could indicate that the sticky layer or waxy layer on the duku's peel has been damaged due to IRE exposure. At the $6 \mathrm{~cm}$ distance of IRE, the duku's peel tissue indicates more compact when compared to the $10 \mathrm{~cm}$ distance of IRE and control. The observations at a magnification of 2500 times with a resolution of $10 \mu \mathrm{m}$ showed that the duku's peel which exposed to IRE within $10 \mathrm{~cm}$ of epidermal skin was damaged when compared to IRE at $6 \mathrm{~cm}$ distance and control.
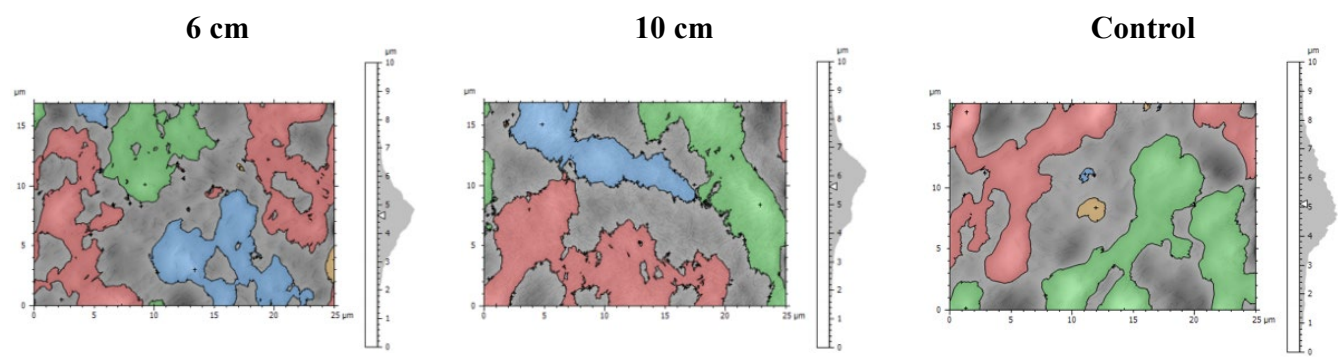

(a) SEM magnification of 100 times
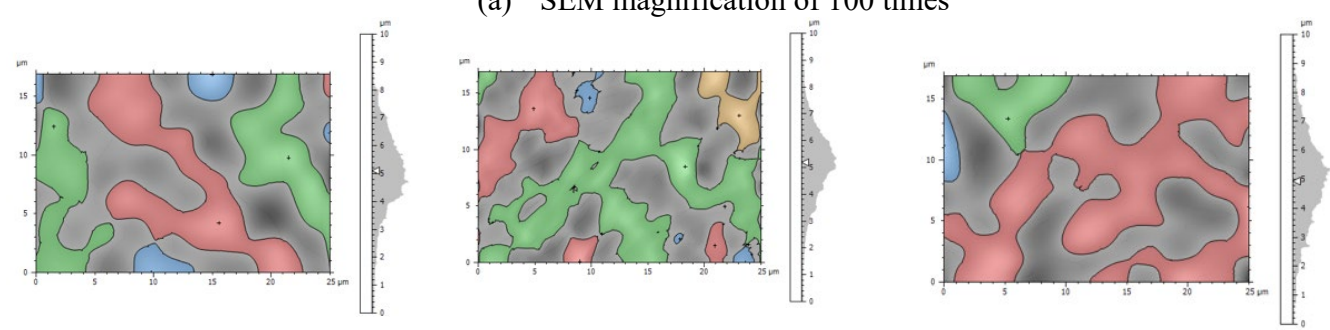

(b) SEM magnification of 500 times
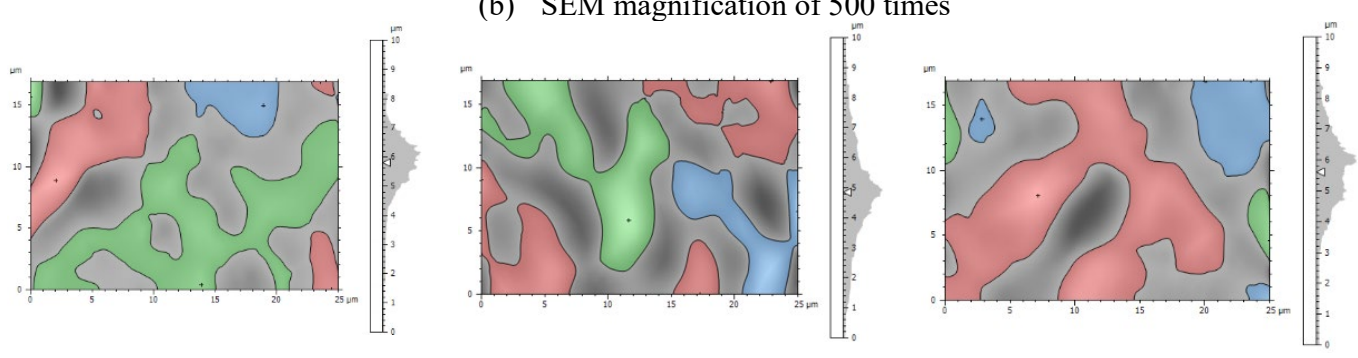

(c) SEM magnification of 2500 times

Fig. 2-a. Topographic reconstruction a single image on duku's peel, presented in perspective format and coloured based on projected area

The manual measurement results were shown in Fig. 1, which reconstructed from a single image to analyze the particles. Fig. 2-a shows that the projected area with 100 times, 500 times, and 2500 times of magnification of SEM method were $33.33 \% .33 .33 \%$ results of the projected area produce the different density values. At 500 times magnification, the density value at IRE $10 \mathrm{~cm}$ has higher value compared to the IRE $6 \mathrm{~cm}$ and control, meanwhile at 2500 times magnification, the density value at IRE $6 \mathrm{~cm}$ has higher value 
than IRE $10 \mathrm{~cm}$ and control. The color result in Figure 2 has a significant correlation with Figure 3 and Fig. 4.

Fig. 2-b. was determined the deepest void in duku's microstructure and the distribution of voids in the dried duku's texture which was represented in red, yellow, green, and blue color. The 100 times magnification result showed that the duku which exposed to IRE had relatively uniform color when compared to the control. At a magnification of 2500 times, it was found that duku exposed to IRE $10 \mathrm{~cm}$ had a relatively higher value of porosity when compared to IRE $6 \mathrm{~cm}$. Rahman [12] states that porosity could be characterized based on size, shape, wall thickness, and pore distribution in the microstructural layer.

In this research, the porosity was carried out in accordance with Rahmawati et al. [11] and focusing in factors which impact the porosity value such as suitability of magnification, resolution, and dept of field values. Porosity is one part that must be evaluated on the dried duku's texture with IRE due to it affects the strength of the agglomerate.
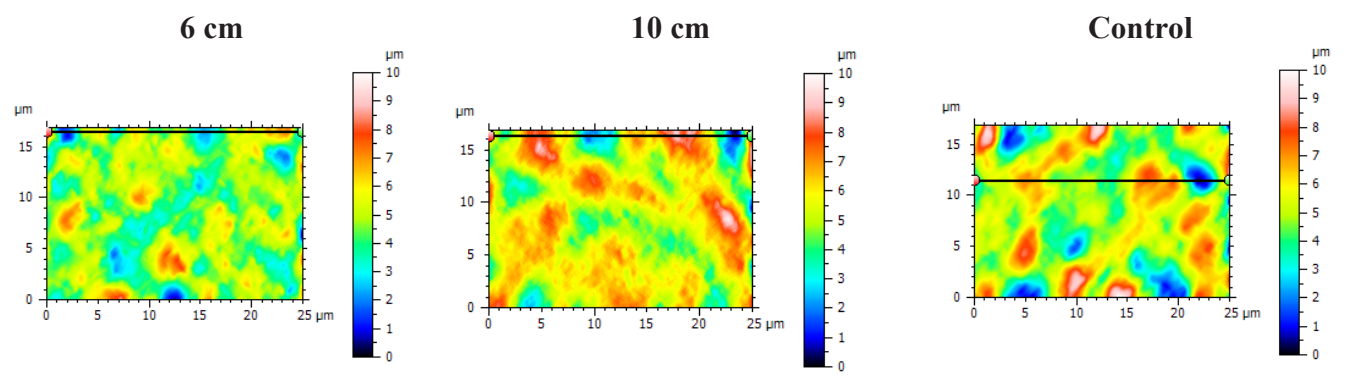

(a) SEM magnification of 100 times
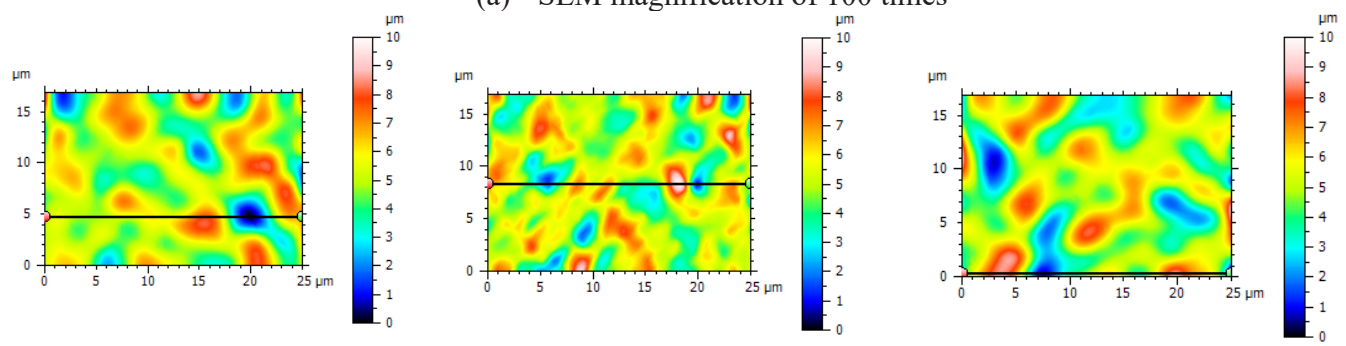

(b) SEM magnification of 500 times
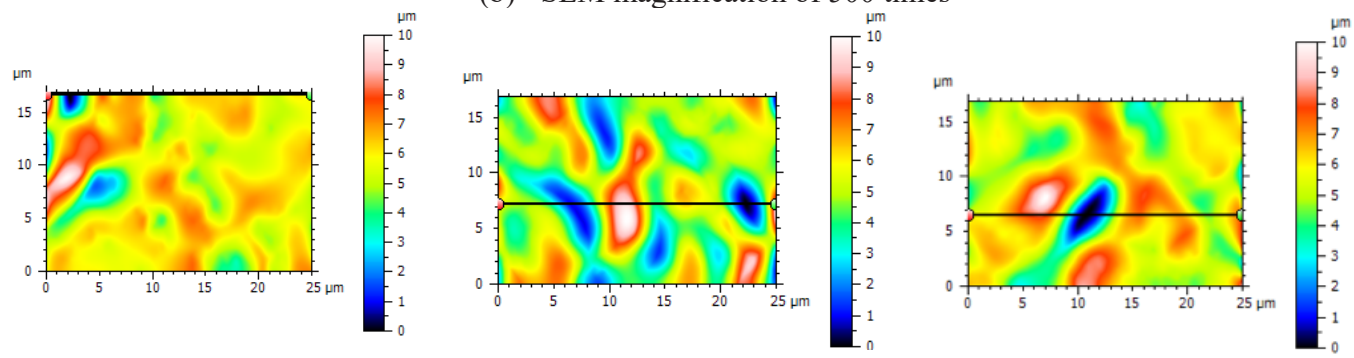

(c) SEM magnification of 2500 times

Fig. 2-b. Distribution void profile of topographic reconstruction a single image on duku's peel

The stage after reconstructed a single image then with Mountain Map Program was 3D visual illustration as shown on Fig. 3. The aims of 3D visual illustration was to determine the the height of the peak and the depth of void. In the previous research Rahmawati et al. [11] stated that the depth of void indicates that the texture surface was did not exposed fully to IRE then causing a decrease the quality of texture tissue hardness and impact to the higher porosity. 
The infrared radiation with a distance of $6 \mathrm{~cm}, 300^{\circ} \mathrm{C}$ and an exposure time of $60 \mathrm{~s}$ with a magnification of 2500 times represent a hill or peak with a relatively uniform orange-red color when compared to the IRE $10 \mathrm{~cm}$ and control (Fig. 3). The red-orange color indicates that a duku's peel was exposed to IRE. The 3D representation of dried duku's peel with exposed to IRE $6 \mathrm{~cm}$ had compact texture when compared to IRE $10 \mathrm{~cm}$ and control. This result was in line with the profile cure result in Figure 4 and the total of porosity (Table 1).
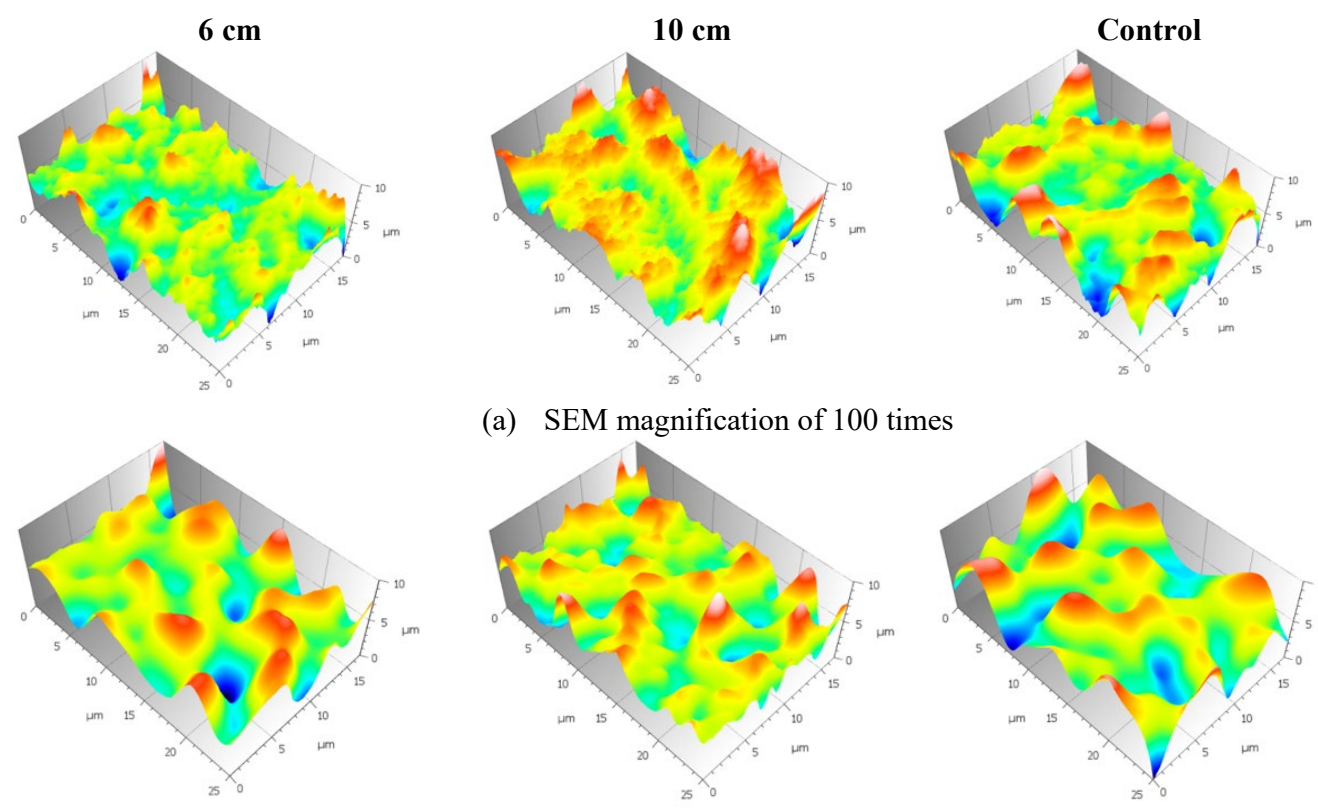

(a) SEM magnification of 100 times
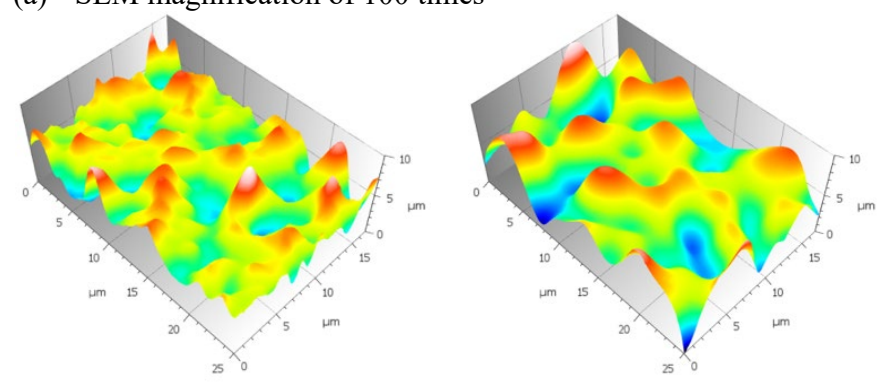

(b) SEM magnification of 500 times
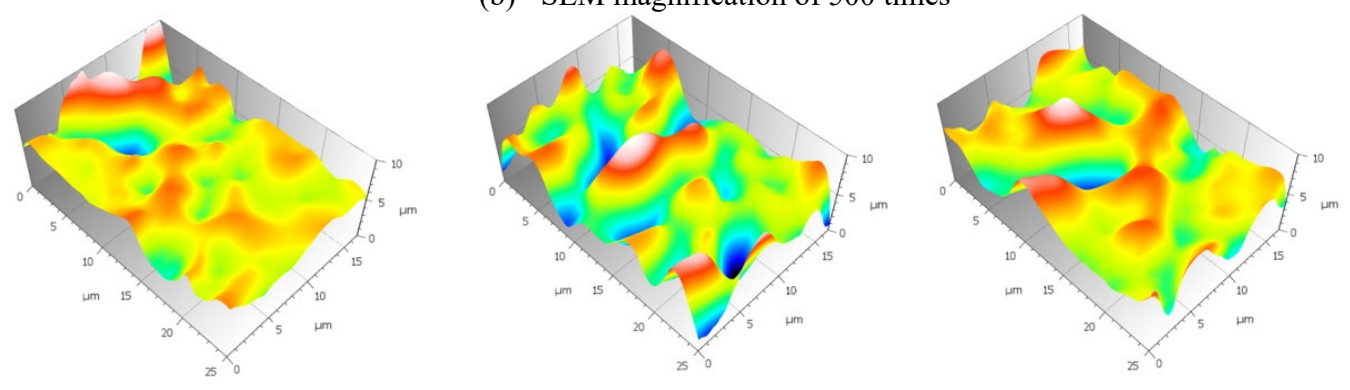

(c) SEM magnification of 2500 times

Fig. 3. 3D visual illustration on Scanning Electron Microscopy.

The profile curve result shows that the duku which was exposed using IRE $6 \mathrm{~cm}$ has relative a stable curve when compared with IRE $10 \mathrm{~cm}$ and control. The stability of the curve shows that the duku's surface was relatively exposed fully to IRE and has minimal porosity. This statement was in line with the porosity result in Table 1.

Table 1 shows that SEM analysis with a magnification of 100 times, the value of porosity in dried duku's peel with IRE $6 \mathrm{~cm}$ was $76.62 \%$, IRE $10 \mathrm{~cm}$ was $77.34 \%$ and control was $95.46 \%$. At 500 times magnification with the distance of IRE $6 \mathrm{~cm}$ was obtained $78.23 \%$, IRE $10 \mathrm{~cm}$ for $92.64 \%$, and control $95.46 \%$. While at 2500 times magnification, duku exposed with IRE $6 \mathrm{~cm}$ was $90.91 \%$, IRE $10 \mathrm{~cm}$ was $146.96 \%$, and control was $131.74 \%$. 

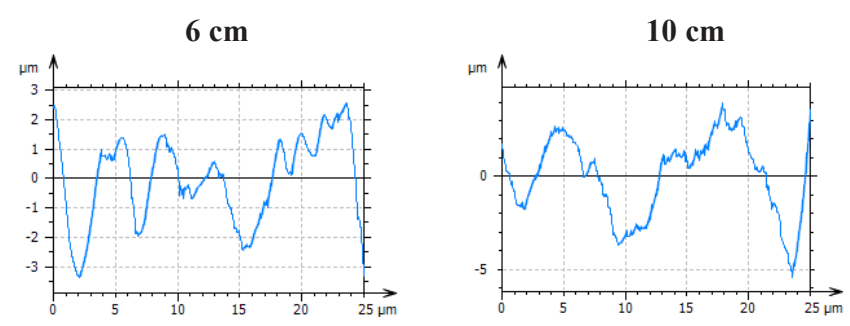

\section{Control}

(a) SEM magnification of 100 times
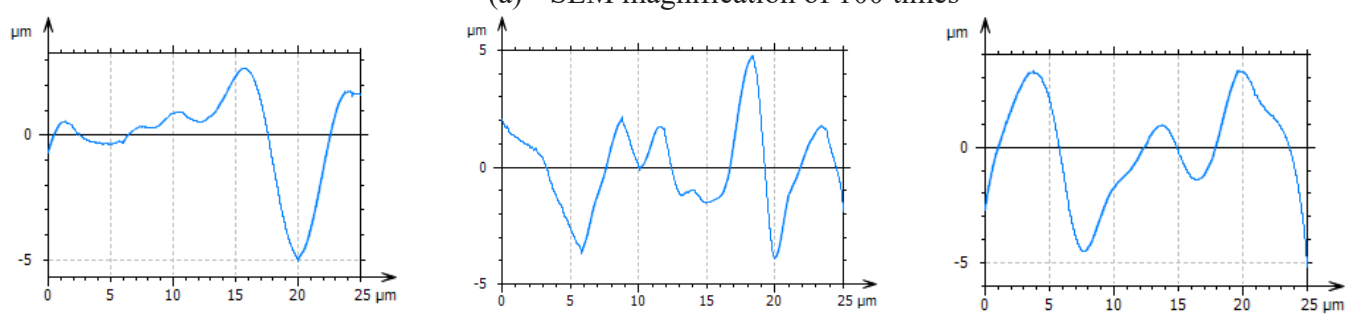

(b) SEM magnification of 500 times
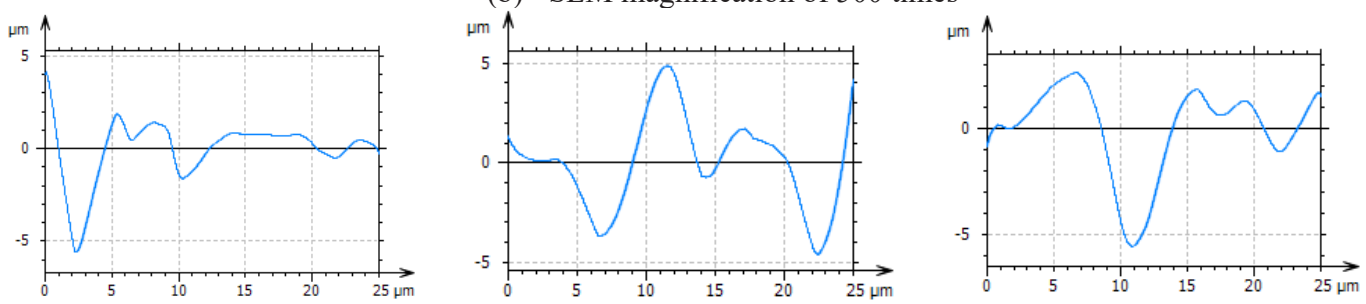

(c) SEM magnification of 2500 times

Fig. 4. Hight profile curve of the pseudo-color corresponding to the 3D topography

The changes in the microscopic characteristics of foodstuffs were caused by changes in their microns. The pore structure of the dried duku's peel which was exposed by IRE at 10 $\mathrm{cm}$ distance could be a facility for a water diffusion or encourages the water during heating and storing process under controlled temperature. On the other hand, the compact structure or less pores of the dried duku's peel which was exposed using IRE $6 \mathrm{~cm}$ could cause a slower moisture transfer during the heating and storing process. The size and number of pores could significantly affect the food texture. The smaller number of pores and the small size causes the structure to become denser. Meanwhile, a higher number of pores and a large pore size can cause a decrease in product hardness.

Table 1. Microscopic evaluate result on duku's peel using Scanning Electron Microscopy

\begin{tabular}{|c|c|c|c|c|c|c|c|c|c|}
\hline & \multicolumn{3}{|c|}{$6 \mathrm{~cm}$} & \multicolumn{3}{c|}{$10 \mathrm{~cm}$} & \multicolumn{3}{c|}{ Control } \\
\cline { 2 - 11 } & $\mathrm{x} 100$ & $\mathrm{x} 500$ & $\mathrm{x} 2500$ & $\mathrm{x} 100$ & $\mathrm{x} 500$ & $\mathrm{x} 2500$ & $\mathrm{x} 100$ & $\mathrm{x} 500$ & $\mathrm{x} 2500$ \\
\hline Number of particle & 200 & 14 & 30 & 610 & 110 & 12 & 109 & 10 & 8 \\
\hline $\begin{array}{c}\text { Density } \\
\text { (particles/mm } / \mathrm{mm}^{2}\end{array}$ & $\begin{array}{c}47 \mathrm{x} 10 \\
4\end{array}$ & $\begin{array}{c}33 \mathrm{x} 10 \\
3\end{array}$ & $\begin{array}{c}71 \\
\mathrm{x} 10^{3}\end{array}$ & $\begin{array}{c}144 \\
\mathrm{x} 10^{4}\end{array}$ & $\begin{array}{c}26 \\
\mathrm{x} 10^{4}\end{array}$ & $\begin{array}{c}28 \\
\mathrm{x} 10^{3}\end{array}$ & $\begin{array}{c}25 \\
\mathrm{x} 10^{4}\end{array}$ & $\begin{array}{c}23 \\
\mathrm{x} 10^{3}\end{array}$ & $\begin{array}{c}18 \\
\mathrm{x} 10^{3}\end{array}$ \\
\hline Projected Area (void) & 33.33 & 33.33 & 33.33 & 33.33 & 33.33 & 33.33 & 33.33 & 33.33 & 33.33 \\
\hline Volume of void (\%) & 1.18 & 1.33 & 1.58 & 1.45 & 1.6 & 1.98 & 1.63 & 1.68 & 1.89 \\
\hline $\begin{array}{c}\text { Volume of materials } \\
(\%)\end{array}$ & 1.54 & 1.70 & 1.75 & 1.88 & 1.73 & 1.35 & 1.71 & 1.65 & 1.44 \\
\hline Porosity (\%) & 76.62 & 78.23 & 90.91 & 77.34 & 92.64 & 146.96 & 95.46 & 102.43 & 131.74 \\
\hline
\end{tabular}




\section{Conclusion}

Our study showed that from the microstructure of dried duku's peel with 3D illustration of scanning electron microscopy with the specification of reconstructing a single image into pseudo-color view and a profile curve the radiation produced at drying distances of $6 \mathrm{~cm}$, $300^{\circ} \mathrm{C}$, and $60 \mathrm{~s}$ has a lower porosity value, and more stable contour when compared to drying with a distance of $10 \mathrm{~cm}, 300^{\circ} \mathrm{C}$, and $60 \mathrm{~s}$ and control. The microtexture condition of duku's peel which was exposed by IRE could create a dry condition as shell-likeness that could maintain the fruit quality and prolong the shelf life.

Acknowledgements. The authors gratefully acknowledge the Ministry of Research, Technology and Higher Education, Indonesia through the PMDSU Project Batch-II and Indonesian Institute of Sciences

\section{References}

1. Z. Pan, X. Li, G. Bingol, T.H. McHugh, G.G. Atungulu, App. Eng. Agric. 25, 935-941 (2009)

2. X. Li, Z. Pan, Food Bioprocess Technol. 7, 1996-2004 (2014)

3. L. Rahmawati, D. Saputra, K. Sahim, G. Priyanto, Potravinarstvo Slovak, J. Food Sci. 12, 744-755 (2018)

4. C. Huang, J. T. Clayton. A Review. In Spiess, W. E. L., Schubert, H. Engineering and Food (Elsevier Applied Science, London, 1990)

5. J. M. Aguilera, D. W Stanley, K.W. Baker, Food Sci. Technol. 11, 3-9 (2000)

6. J. Wilson, Microscopical methods for examining frozen foods, In Food Freezing: today and tomorrow (Springer, London, 1991)

7. P.M. Falcone, A. Baiano, A. Conte, L. Mancini, G. Tromba, F. Zanini, M.A. Del Nobile, Adv. Food Nutr. Res. 51, 205-263 (2006)

8. L. Rahmawati, D. Saputra, K. Sahim, G. Priyanto. Study of using infrared radiation for increasing the shelf life of $d u k u$, in Proceedings of the International Symposium of International Society for Horticultural Science, Acta Hortic, ISHS 2018, Jeonju, South Korea (2017)

9. X. Li, Z. Pan, Food Bioprocess Technol, 7, 2005-2013 (2014)

10. C. Ding, R. Khir, Z. Pan, L. Zhao, K. Tu, H. El-Mashad, T.H. McHugh, Food Bioprocess. Technol, 8, 1149-1159 (2015)

11. L. Rahmawati, D. Saputra, K. Sahim, G. Priyanto, Slovak. J. Food Sci. 14, 292-299 (2020)

12. M. S. Rahman, Drying Technol, 19, 1-13 (2007) 